\title{
A Research on the Mechanism and Platform Construction of Public Geological Achievements Sharing
}

\author{
Jianping Ge, Bing Zhong and Yalin Lei \\ School of Humanities and Economic Management, China University of Geosciences, \\ Beijing 100083, P.R. China \\ duoduo198229@163.com zhongbing0126@163.com leiyalin@cugb.edu.cn
}

\begin{abstract}
Public geological achievement platform is a part of science and technology infrastructure and related to sustainable development of the economy and society. By literature research, expert's discussion and case study, the paper proposes that centralized sharing with local sharing mechanism and multi-layers network have to be set up to achieve public geological achievements sharing. The operating mechanism regarding integrating mechanism, grading mechanism, sharing manners as the kernel, and sharing guaranteeing mechanism mainly including the outlay investment, policies and legislation, organizational operation, human resources, technical standards and criteria are discussed in detail in this paper. The paper also puts forward two problems which concerns secrecy and rational pricing of public geological achievements, which need further discussion.
\end{abstract}

Keywords: Public geological achievements, Platform construction, Sharing mechanism

\section{INTRODUCTION}

Public geological achievements are those valuable geological information and material information achieved by geologists, who applied scientific knowledge of geology and exploration technical measure into the research on geologic bodies, including geological map, geological database, and mineral information report, related serial publications, special report and so on. Public geological achievements are supported by public finance, shared by the society. For example, geological maps that collected from geological mapping work which are financed by the government are provided to the society at the price of producing cost, all the social members have the equal usufruct.

The sharing of public geological achievements is necessary. On the one hand, public geological achievements thanks to the work of geologists have powerful practical value and increase social benefits constantly. They could achieve the most utility only by sharing. On the other hand, the taxpayers support the public finance by paying taxes, and the public finance offers the necessary cost of the achievements. According to the principle that people should benefit from his invests, public geological achievements should be shared.

Please use the following format when citing this chapter:

Ge, J.. Zhong. B., Lei. Y.. 2007, in IFIP International Federation for Information Processing. Volume 254. Research and Practical Issues of Enterprise Information Systems II Volume 1, eds. L. Xu, Tjoa A., Chaudhry S. (Boston: Springer). pp. $569-578$ 
The services of public geological achievements sharing in foreign developed countries are ahead of that in China. They have set up the modern geological information service systems. Since the WWW server of USGS started to run in 1993, these developed countries have initiated online geological information services successively. In terms of the service provider, in addition to the traditional service providers, such as national, provincial or state Geological Survey and their professional institution, Geological Survey also bring some privately owned geologic research institutions, universities, even individuals into geological information providers through partnership mechanisms in the United States, Britain, Canada, Australia and other developed countries. They have established agent or value-added agent mode simultaneously. In terms of the service content, the United States, Canada, Australia, Britain and other countries have enacted Freedom of Information Act to determine the sharing of resources including simulated information resources, physical geological data and a variety of digital information and databases, while the services have continuing extended. For example, Australia information services have been expanded to various outdoor recreations [1]. In terms of clients, in addition to the traditional government institutions, enterprises, research and education institutions and the public, these developed countries have pointed out definitely the strengthening of information services for special groups (disabled and aboriginal peoples). USGS has set up a special website to satisfy this requirement [2]. In terms of the service approach, public geological achievements are shared through the online services system on the network, such as query and search system of various catalogues, browser and search system of special topic, Web Mapping system and one-stop service system, etc.

Comparing with foreign countries, domestic public geological achievements sharing service system in China has the main gaps as following [3]: In terms of the service provider, there is no unified providers, no multi-levels and multi-units to provide related services in our country; there is no agent and value-added services on the whole; it's lack of coordination among service providers. In terms of the service content, domestic services are mainly about borrowing, reading and duplication of the papery documents; the content of information services are limited greatly; CGS website provides very little online service and practical valuable professional information; most content of the websites just like "about us " in foreign corresponding websites [4-5]. In terms of the clients, the main users are professional geological survey staff in China. Among the readers and users of geological documents in 2003, the geological and mining industry units accounted for $31 \%$ of the total users, of which is the highest proportion; the metallurgical, chemical, nonferrous metals, earthquake and other industries units accounted for more than $20 \%$ of the total users [6]. In terms of service approach, the domestic services manners are the combination of traditional service and modern service, while the former is the primary one. Data processing and providing of the databases basically adopt the offline manner. Generally speaking, one database has one system only to support the online search, browse and downloading of part of the information [7].

From the above analysis, it's needed to establish harmonized sharing platform which can provide practical valuable information and online services to improve the technical level of information services and develop the systems which support integrated services. From this perspective, the paper discusses the building framework 
of sharing platform, sharing operating mechanism and sharing guaranteeing mechanism of public geological achievements for the purpose of efficient and realtime sharing. The construction of framework is regarding sharing as the core, achievement data clusters as the foundation, users as the terminal, platform as the physical approach, policies and rules as the guarantee. The sharing platform is made up of multi-layers organizations such as physical layer, data layer and network layer, and integrates related technology. The domestic platform needs to joint the foreign platform when it has been built completely in order to realize the intercommunion and mutual aid. Sharing operating mechanism is the manner and approach to share the achievements. The sharing process is completed by the achievement providers and users. The achievement providers appear in the form of virtual alliance to offer the standardized achievement data and entity. Under the guidance of sharing principle, those providers choose the appropriate sharing manner and provide sharing services to the achievement users followed by the established procedures. Achievement users should feedback the scientific data to platform and those providers after finishing sharing in order to promote the renewal of the achievement data. Sharing guaranteeing mechanism is the various measures to achieve the normal running and sharing of the platform, including the outlay investment mechanism, policies and regulations guaranteeing mechanism, operation guaranteeing mechanism of an organization, human resources guaranteeing mechanism, technical standards and criteria mechanism and so on.

\section{METHODS}

The main methods are literature surveying and Delphi method. At the same time, we consulted many related experts of the geological museum of China and national geological archives of China. Through the literature survey, we grasped the status and features of socialized services of foreign public geological information and understood the technical methods and models of information sharing. It is helpful to absorb all the useful ideas, grasp the status and features of public geological achievements sharing and improve the sharing scheme and mechanism by Delphi method. At last, we could make the construction of sharing platform and sharing mechanism feasible and scientific by consulting the practitioners and testing run with the examples.

\section{THE BUILDING FRAMEWORK OF PUBLIC GEOLOGICAL ACHIEVEMENTS PLATFORM}

The platform of public geological achievements is an important component part of national innovation system and the basic support system which provide services for geosciences progress and technological innovation. The platform utilizes fully the information, the network and other modern technique, integrates and optimizes 
systematically the public geological achievements in order to promote high-efficient allocation and comprehensive utilization of the achievements within the range of the whole society, and maximize the benefits of achievements.

\subsection{Idea of Construction}

The sharing achievements include the achievements having been public, the achievements to be public in the future and some confidential achievements because of security and intellectual property rights. Therefore, the platform combines centralized sharing with distributed sharing, builds network centre and sub-centre which combines distributed sharing and centralized sharing [8]. Currently, we should continue to perfect distributed and centralized database cluster on the basis of the construction of fundamental geological database of more than $\mathbf{3 0}$ different fields and part of geological achievement database; set up achievement data standards and criteria that many units would follow together; establish a set of technology integration of software and hardware on the network to guarantee sharing. Referred to present research result [9], the basic idea of the construction of public geological achievements platform is illuminated as figure 1.

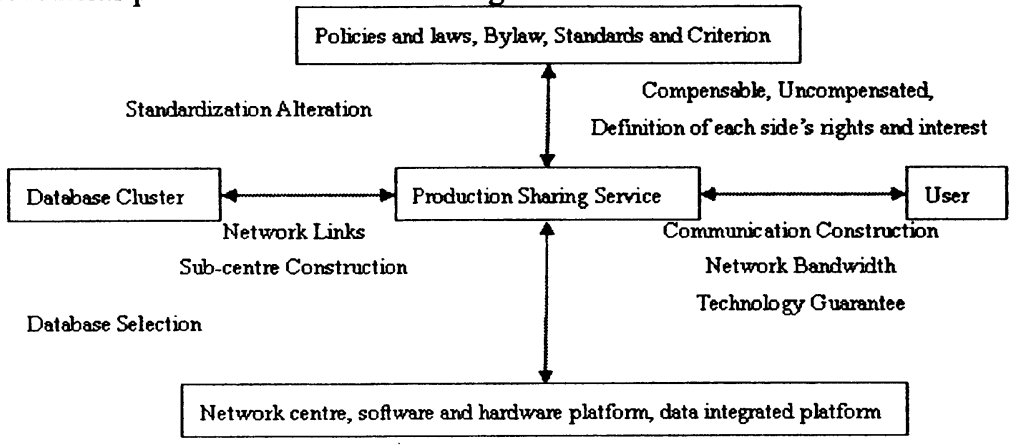

Figure 1. The Basic Idea of the Construction of Public Geological Achievements Platform

\subsection{Sharing Network Centre and Sub-centre [9-10]}

Both network centers and sub-centers, as the support of achievements sharing network system link with Internet. Network centers have the function of user authentication and own Web server, GIS and application server and database server. Through public geological achievements sharing website and metadata server, the users could browse and query the texts, statistics and spatial data in the public geological achievement sharing database quickly and conveniently. In addition, the network systems also include network system, development platforms, various of hardware and software of server, subsystems of communications, interfaces, security 
strategy, optimization of hardware and software system integration channel, and the construction of distributed database.

\subsection{The Construction of Multi-layers Architecture of Sharing Platform}

As a network platform of achievements sharing, we must build a multi-layers architecture to provide users with various services by integrating related technology. The structure of public geological achievements platform include the achievement physical layer, database layer and the network layer, as illustrated in figure 2 . Hereby, some research results may be referred to [11].

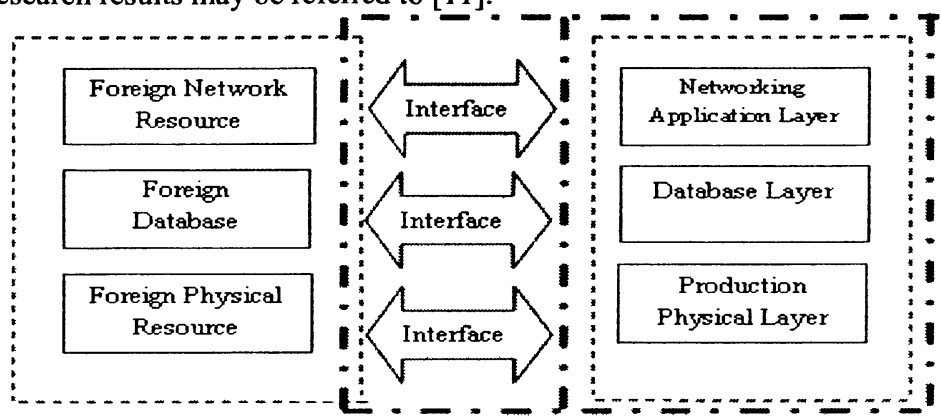

Figure 2. The Structure of Public Geological Achievements Platform

Physical layer is the physical performance of platform resources carrier of public geological achievements. It is mainly about public geological physical achievements, such as geological map, papery form of various reports, hardware equipment and support software system in the network technological environment.

Database layer is a digitized form expression of containing resources of physical layer. It is the integration of the digitized resources of the platform; at the same time, the database layer is the foundation of information resources of network layer of the platform. The organic combination of the database layer, the physical layer and the networking application layer form jointly the overall structure of the platform, including various-scales geological map database, mineral area database, geochemistry database and physical geographic database etc.

Networking application layer is the most basic support system of the construction of public geological achievements sharing platform, the important information service form of the platform and the important approach that the users could obtain the achievement information, including network application environment and management information \& service information system of the achievement resources.

The construction of these three layers has to be done in order. Database layer could only be established after finishing the integration of the physical layer. Then the sharing of the network layer may be realized. 
Linking with the foreign resources could help to improve further the technology of the platform and the mechanism after completing the construction of the domestic platform. This interface is the construction of talent and resources, the integration of technology and standards, and the unblocked mechanism as well as the cooperative channel [12].

\section{THE OPERATING MECHANISM OF PUBLIC GEOLOGICA L ACHIEVEMENTS SHARING}

Public geological achievement sharing is the process that achievement owner provides certain public geological achievement to user while sharing platform and sharing manners and achievement user should feedback the information and data produced in the sharing course to sharing platform and achievement owner. It is necessary to set up and realize the achievements' combining, grading mechanism and sharing manners to support the sharing process.

\subsection{Achievements' Combining and Grading Mechanism of Sharing}

Public geological achievements' combining is the foundation of sharing realizing. At present, public geological achievements' obtaining is mainly supported by governmental investment in our country. But because of lacking top floor designing of investment and macroscopically coordinating management, the exchanging of achievement becomes to be an obstacle. For a long time, these public geological achievements are distributed in different organization units and individuals. Therefore, combining achievements from different sources which can be shared and confirming the sharing range and setting up a unified norm and filing for achievement information are the inalienable contents of achievements' combining mechanism.

The value of utility of public geological achievements will differ if the concrete contents that each achievement displays or the purpose of users are different. So achievement sharing not only needs to be thought about the entire social benefits increasing progressively, but also should be considered to guarantee the national security and the intellectual property rights. Only good sharing order and sharing grading mechanism are establishing and perfecting gradually, the effective achievement sharing can be realized. Sharing grading mechanism mainly based on whether the sharing behavior endangers national security and benefit. This foundation is used to determine that some achievements are brought into secret operation mechanism or make strict and explicit using stipulation.

\subsection{Sharing Manners}

Sharing manners are the concrete operating modes which both sides achieve achievements exchanging through the corresponding form, method and procedure. 
Sharing manners decide adjustment of benefit relations among the country, the society and both sides and act as the core and the key to stimulate the vitality of the sharing platform work.

The establishment basis of sharing manners includes the sharing goal and the security.

1. The Sharing Goal

Sharing manners can be divided into free sharing and paid sharing according to whether sharing behavior takes seeking to make a profit as the goal.

Free sharing refers to the achievement owner no longer to demand achievement cost fee when offers user sharing. Achievement cost fee has included the expenses of gathering, processing as well as preserving. Free sharing can be divided into the following three kinds:

Free entirely sharing refers to achievement owner does not charge any fee when provides achievement sharing.

For certain achievements which do not have the direct sharing condition or should be retreated according to user's request, achievements' owners could charge the retreating expense when provide these achievement.

For certain achievements whose sharing need manpower disbursement and cartage expense, users should pay the corresponding service fee.

Paid sharing is the way that achievement owner gather certain proportion of the achievement cost from user by different methods when provides achievement sharing. The public geological achievements here refers are whose investors cover the country, the collective and the individual. One kind of paid sharing is state investment. In this situation, the main constitution of the achievement funds is financial allocation and the few is the collective accumulation; perhaps the achievement gainer originally is the governmental agency or the enterprise organization and the gainer recently transferred to company which had left behind the state financial allocations ingredient. Paid sharing can be divided into profit-making sharing and non-profitmaking sharing according to the using goal.

Non-profit-making paid sharing refers to enterprise units demand achievement to develop themselves or undertake the duty which the country issues.

Profit-making paid sharing refers to the following two kinds of situations: first kind is using achievement to develop achievement or management; second kind is deep processing achievement and gaining profit by forming achievement and information which the market requires.

Regarding non-profit-making paid sharing, achievement owner should gather lower achievement cost. On the contrary, regarding profit-making paid sharing, achievement owner could gather higher achievement cost.

2. The Security

The achievement security refers to the sharing behavior whether possibly threatens the national security, the resources security, the public health security and the biological security.

For the achievement which has the possibility of safety threat, the user must apply for the administration to permit beforehand and only can carry on sharing after obtaining the administrative permission. It is called administrative permission sharing way. 
In "Mapping Supervisory work Country Secret Scope Stipulation", the second item has stipulated country confidential grade and the table of the mapping supervisory work and these achievement sharing scope receive the strict limit. Like "the mutual transformed parameter among the national earth coordinate system, the geocentric coordinate system and the independent coordinate system" is the national top-secret item, the sharing scope is controlled strictly in "the mapping achievement storage unit and the user who has been authorized by the national survey service", "the military mapping achievement storage unit and the user who has been authorized by the general staff survey service". Without permission and authorization by department concerned, these achievements all can not be shared.

Based on the above two foundation, the sharing manners of public geological achievements can be divided into paid sharing, free sharing and administrative permission sharing. Certainly, the sharing manners can also be specifically divided into transacting sharing, renting sharing, cooperating research sharing and exchanging sharing and so on according to the different sharing behavior.

\section{THE GUARANTEEING MECHANISM OF PUBLIC GEOLOG ICAL ACHIEVEMENTS SHARING}

The guaranteeing mechanism of public geological achievements sharing is to secure efficient sharing and sustainable development of the platform, including various measures, policies, laws, regulations, management systems and so on.

In the aspect of outlay investment, it is to change the one-off investment of the construction at present, reinforce the running support of later stage and build up a set of investment system which is diversified and sustainable development.

In the aspect of policies, laws and regulations, it is to consummate the "Mineral Resource Law" and other fundamental laws, "Provide and Utilization of the Public Geological Data Interim Measure" and other administrative laws, "National Geological Data Collection Management Measure " and other administrative rules and regulations, suggest enacting "Technological Resource Sharing Law" and other fundamental laws, "Public Geological Achievement Sharing Regulation" and other administrative laws and related administrative rules and regulations, solve the problems such as the protection of the intellectual property rights, rational pricing and the protection of sharing rights and interests of each side.

In the aspect of the guarantee of the running of the organization, vertically, it is to establish unified leadership organization which takes Chinese Geological Survey as the platform, management organization which takes geological survey centers directly under China Geological Survey in $\mathbf{6}$ areas as sub-platform, in order to take charge of the construction, maintenance and running of the central and local platform; horizontally, the platform adopts the council system which takes the council as the highest decision-making organization, the platform administrative center as the decision implementing organ, the expert consultative committee as the decision support organ and the supervise council as the platform supervise organ.

To guarantee the supply of required human resource, effective talent employment mechanism, reasonable structure of talents, and scientific post setting 
and employment system as well as the realization of effective incentives should be established.

For technical standards and criteria, we need to establish the unified description standards, scientific data standards and quality administrative measurements of data.

\section{DISCUSSION AND CONCLUSIONS}

Public geological achievement sharing has just started in our country. Many achievements have been obtained while lots of insufficiencies still exist. The construction of the public geological achievement platform is to solve the problem of barriers of sharing, promote the establishment of national innovation system and the sustainable development of the resources.

The public geological achievement platform is built up on the basis of more than 30 fundamental geological databases and the achievement resources database at present. Considering confidentiality, intellectual property rights and other factors, the platform needs to achieve the object-oriented services, adopt the combination of centralized sharing and distributed sharing, establish the networking centers and subcenters, and construct a multi-layers structure of the platform. This is the conception of platform construction which the article proposes.

In addition to the entities guarantee, the realization of achievement sharing also needs to establish the operating, guaranteeing and other mechanisms. The operating mechanism mainly includes the integrating and sharing graduation mechanism, the sharing manners. The guaranteeing mechanism includes the outlay investment, the policies laws and regulations, the running of organization, the human resources and the technical standards and criteria. Only on the basis of the guarantee of the coordination and integrity of the entities and soft mechanism, public geological achievements sharing could realize. Certainly, in the process of the constant communication with other countries, domestic technology development and the experience accumulation, it also needs to update the platform and sharing mechanism constantly to achieve sustainable development.

Limited by condition, the following two problems need to be further studied in the future.

1. The Problem of the Sharing Confidentiality

Parts of the public geological achievements aren't able to be public temporarily. The reason is the technical problem or the related national security requirements. But there has not been an explicit standard to define the scope of secret information yet. From the experience of abroad, the way to solve this problem is possibly to grasp the scale of confidentiality through "the use conditions", which is to limit sharing by the users' verification, such as in Australia, but this manner is affected deeply by the influence of subjective judgment factor.

2. The Problem of Rational Pricing

One part of the public geological achievement is non-profit, the other part is profit. Both of them are related to the problem of pricing. For the former, the achievement providers should provide the achievements to the users free of charge or 
at a price only with necessary cost, the service fee etc. However, the cost of each kind of the achievements is different, and the sharing groups are indefinite. How to calculate the expense needs to be defined. For the latter, the achievement providers could confer with the users on the price in the principle of the marketing. If both sides are to negotiate a price, the price may be too high or too low. Too high would hinder the transform of the geological achievements, while too low will damage the devaluation of the state assets. Therefore, whether a guide price should be and how to be fixed by the government needs further discussion.

\section{REFERENCES}

1. Z. Jiang, The current situations and characteristics of geological information service in developed country, Strategic Research References on Geological Work (Inside). Volume 7, pp.1-15, (2006).

2. USGS, U.S. Geological Survey 2000-2005 Strategic Plan, USGS (1999). http://www.usgs.gov/stratplan/ (Accessed May 20, 2007).

3. M. Zhang and Q. Lee, Geoinformation work today at China geological Survey, Map Asia (2004).

http://www.gisdevelopment.net/application/geology/geomorphology/ma04296.htm (Accessed May 22, 2007).

4. Website of China Geological Survey, CGS. http://www.cgs.gov.cn (Accessed May 20, 2007).

5. Website of Development and Research Center of China Geological Survey, DRCCG. http://www.drc.cgs.gov.cn/ (Accessed May 20, 2007).

6. Development and Research Center of China Geologic Survey, Research on the Strategy of Geological Work, in Proc. of Youth Branch of the Institute of Geological Economics in China Annual Conference, eds. Youth Branch of the Institute of Geological Economics in China (Earth Publishing House of China: Beijing, December, 2005), p.79.

7. Website of National Geological Archives of China, NGAC. http://www.ngac.cn/ (Accessed May 20, 2007).

8. X. Fu, T. Chi, Y. Shao, and J. Bi, The research and development on China's sustainable development information sharing system, Geographical Information World. Volume 12, pp.32-36, (2003).

9. X. Fu, X. Li, and J. He, Research and Construction Progress on China Sustainable Development Information Sharing Based on The Network, China Basic Science. Volume 1, p.71, (2003).

10. S. Quaglini, Information models for data sharing, Neurol Sci. Volume 27, pp.281-283, (2006).

11. The seminar of the implementing scheme of the National Science and Technology Basic Terms Platform Building, The Overall Research Paper of the Implementing Scheme of the National Science and Technology Basic Terms Platform Building (Inside), p.15, (2005).

12. F. Harvey, W. Kuhn, H. Pundt, Y. Bishr, and C. Riedemann, Semantic interoperability: A central issue for sharing geographic information, The Annals of Regional Science. Volume 33, pp.213-232, (1999). 